\title{
Economic crisis and public attitudes toward science: A study of regional differences in Spain
}

\author{
Luis Sanz-Menéndez, Email: Luis.Sanz@csic.es \\ Institute of Public Goods and Policies (IPP), Consejo Superior de Investigaciones \\ Científicas (CSIC), Madrid.
}

\section{Gregg G. Van Ryzin}

School of Public Affairs and Administration, Rutgers University, Newark.

\begin{abstract}
Although there is little theory about the effects of economic conditions on public support for science and technology (S\&T), some evidence suggests that an economic crisis could produce a decline in support of S\&T because of more pressing priorities, such as jobs and social services. But the public may also view S\&T as a strategic pathway out of an economic slump. We test these competing hypotheses employing two national surveys from Spain, implemented before (2006) and after (2010) the onset of a severe economic crisis. We find that, in regions hit hardest by the crisis (compared to less-affected regions), trust in the benefits of S\&T increased substantially, as did general public interest in S\&T. Similarly, residents of the hardest-hit regions were more likely after the crisis to choose S\&T (out of a list of policy areas) as a priority for government, and somewhat more likely to express support for increases in government S\&T spending. Theoretical and policy implications are discussed.
\end{abstract}

Key words: Public opinion, Government spending, Interest in science, Science policy, Public policy 


\section{Introduction}

The financial downturn that started in 2007, and then accelerated with Lehman

Brothers' bankruptcy in 2008, has been transformed into a global economic crisis. The crisis has contributed to significant increases in unemployment levels, the insecurity of many groups in society, and fears about the future. The effects of economic insecurity on citizens' general attitudes and values have been anticipated by the general hypothesis of postmaterialism transformation (Inglehart \& Abramson, 1994). In the second semester of 2010, for example, more than $52 \%$ of Europeans believed that "tackling poverty and social exclusion should be given priority" as a policy, with an increase of 8 points compared to a previous survey early in the same year (Eurobarometer, 2010a). There was already evidence of a general support towards welfare state spending in the 1990s (Svallfors, 1997; Taylor-Gooby, 2001) and explanations of national variations (Blekesaune \& Quadagno, 2003; Fraile \& Ferrer, 2005), but the crisis seems to be contributing significantly to change in the aggregate general attitudes and preferences of citizens regarding government priorities. These trends have been reported recently in the Spanish context (Agencia de Evaluación y Calidad [AEVAL], 2011)

But have public attitudes towards science and technology (S\&T) changed as consequence of the crisis? Regarding S\&T, there is contradictory empirical evidence. In Europe in 2010, 14\% of the citizens thought that R\&D should be a priority, with a small increase of 1 point in comparison with the previous semester (Eurobarometer, 2010b). At the same time, in the US, the comparison between the pre-crisis and post 
crisis has seen a reduction in those that believe that $R \& D$ is receiving less money than is necessary (US NSF, 2012), while support for other policy areas, like education, has dramatically increased. However, general results of the 2010 surveys in Europe and the US -when not compared with other policy areas- present similar levels of interest, support and positive attitudes towards science than the previous pre-crisis surveys.

Despite these results, there is evidence that, when confronted with more pressing priorities such as jobs and cuts in social services, citizens are likely to change their priorities in terms of government action. The priority assigned to welfare policies, especially those related with unemployment protection and the fight against social exclusion, increase in times of crisis. In contrast, other policies, such are security, defense or environmental protection, tend to see a reduction in the priority attributed by citizens and in the assessment regarding the allocation of government resources (Quadagno \& Peterson, 2012; Kam \& Nam, 2008; Svallfors, 2003).

At the same time, the crisis has also impacted government spending itself. After various government stimulus packages, in which science and technology had a relevant role (OECD, 2009), and the bailout of some Euro countries (Greece, Ireland, Portugal), the dominant government policy adopted in Europe has been one of fiscal consolidation, meaning significant budget cuts in many areas of public spending. Policy priorities with respect to the areas of public spending protected from these cuts have varied quite a bit among countries, but still governments had to make hard choices among different areas of public policy. While some governments increased the priority given to S\&T, others, like the Spanish government, significantly cut their science budgets and reduced support for research (Science, 2012). In this context, broad 
support among the public could become a relevant factor in protecting policies from budget cuts; if so, then knowing about changing citizens' attitudes towards science is clearly important.

While there is some evidence about what determines attitudes of the public towards science generally (Allum et al., 2008; Bauer et al 2007; Bauer 2009; Miller 2004; Pardo \& Calvo 2002), little is known about the factors influencing changes in citizens' preferences for science, particularly the effects of major shifts in economic or political conditions. Thus, the aim of this paper is the analysis of change in public attitudes toward science and technology (S\&T), as well as support of government S\&T spending, in the context of the European economic crisis. Specifically, we focus on the Spanish case, a country that has suffered a very rapid increase in unemployment levels, yet with substantial variation in the severity of the crisis across Spain's 17 regions.

\section{Analytical background and hypotheses}

In this paper we aim to analyze two different but complementary issues: change in public attitudes toward science and technology (S\&T), as well as change in support of government S\&T spending. In doing so, we will address two different streams of literature related to public understanding of science (PUS) and citizen's preferences regarding government spending and global value changes.

To begin with, there is a rich research tradition regarding citizen's attitudes towards science that has accumulated evidence about the general determinants of attitudes towards science and technology (Bauer et al., 2007; Bauer, 2009). The levels of awareness, interest and substantive knowledge concerning science issues by the public 
have been used to account for various general attitudes towards science. The dominance of the so called public deficit model has been widely noted (Sturgis \& Allum, 2004). Initially, the field focused on scientific literacy (Miller, 1983a; Miller, 1998), with concerns about the limited scientific knowledge of the public. Later, interest emerged in the broader public understanding of science (Miller, 2004), moving the research agenda from knowledge to attitudes and to a more complex analysis of the public's view of science in society. Additionally, when the analysis moves from general attitudes toward science to more concrete fields of science, studies have found significant levels of ambivalence (Bauer, 2002, Nisbet, 2005). Personal attributes like age, gender, education, political ideology or religious beliefs have been found relevant to understand attitudes towards science, but individual beliefs vary greatly from one society to another, according to various institutional factors and social structures. Different factors - such as the level of affluence, the different social structures, or varying expenditure levels in a policy area - may also affect attitudes toward science and general values.

In fact, there are significant variations in national attitudes towards science (Miller et al., 1997), with some studies suggesting a negative relationship between the level of development or industrialization of societies and the level of support or acceptance of science (Bauer et al., 1994; Durant et al., 2000), indicating that the most developed societies have become more cautious regarding S\&T (Gaskell et al., 1999). These findings were referred to as the post-industrial model of PUS, suggesting that bellow a certain level of development there are more positive attitudes towards science, while beyond that point increasing knowledge drives more sceptical attitudes towards 
science. The existence of a scientific ideology or scientific myth, moreover, was found to be negatively correlated with the level of development (Bauer, 2009). Even in the Spanish case, there is evidence confirming more positive attitudes in science and technology in less developed regions (Quintanilla \& Escobar, 2005; Quintanilla et al., 2011).

In fact, some of the arguments about the postmaterialist transformation in values (Inglehart, 1990) could be used to account for the negative relationship between the level of economic development and ambivalence regarding science. The general argument will be that a high level of development in a country (or a region) and a high income level tend to moderate the demands of citizens for public intervention and more materialist policies (Inglehart \& Abramson, 1994). Because postmaterialist values and affluence are associated, citizens in advanced industrial societies may take science and technology for granted in the same way as economic security and basic material conditions. Thus, the post modern hypothesis provides us with some expectations regarding the potential effects of an economic crisis: prosperity increases post materialist values, while scarcity turns people back toward materialism (the scarcity hypothesis) (Inglehart, 1990).

Despite the fact that the origin of the field of public understanding of science, in the late seventies and early eighties, was originally associated with an interest in understanding citizens' support for government spending on science and technology (Miller, 1983b), research on PUS has more recently focused on more general attitudes towards science with very little attention to public support for government S\&T spending. This is perhaps due to the fact that, in the area of public understanding of 
science, it has been largely assumed that positive attitudes towards science translate automatically into to public support for more government spending on S\&T. Only recently some confirmation has been found that interest in science (and factors relevant for explaining positive attitudes towards S\&T in general serve also as an explanation of the perceived priority and expressed support by citizens for more government S\&T spending (Muñoz et al., 2012; Sanz-Menendez et al., 2013). With respect to citizens' support for government spending in other policy areas, we also know that policy preferences and their determinants vary substantially, depending on the sector of public policy. For example, public preferences regarding welfare state policies (health, education, pensions, or unemployment benefits) seem to respond to a more coherent structure of determinants (Jacoby, 1994). Additionally, the different contexts as well as the features, expectations or outcomes of these policies are also likely to condition citizens' attitudes toward public spending (Svallfors, 2003). As a result, a single structure of determinants of attitudes towards public spending cannot be applied across all public policies and programs (Monroe, 1979; Sanders, 1988).

While prior studies have identified some relevant variables as important for explaining public support for government spending on $S \& T$, in the context of policy choices, there is no clear theory regarding the effects of an economic crisis on public support for science and government spending on S\&T. However, evidence from the effects of crisis on public opinion in other areas of public policy, such as the environment, and the short term effects of the economic crisis on a return to materialist values (Inglehart \& Abramson, 1994), point to a potential hypothesis about attitudes toward science and S\&T spending.. In line with the expectations emerging from the theory, Scruggs \& 
Benegal (2012) have found that economic downturns are associated with reduced trust in climate science and less concern about climate change, meaning that the environment and environmental policies seem to reflect postmaterialist values. In fact, we believe that an underlying assumption of most of the PUS literature is that science and technology, and related government spending, belong to the postmaterialist domain; if so, then the expectation would be a reduction of citizens' support in times of crisis. But this assumption should be subjected to an empirical tests, which we do in our study.

Based on this diverse empirical evidence, the post-industrial model of PUS, and the underlying theory of postmaterialist values, we can identify two opposing expectations for the potential impact of the crisis on attitudes towards science and public spending on S\&T in Spain.

First, some of the prior studies on government spending preferences would seem to suggest that public support for S\&T in a time of economic crisis should decline in the face of more pressing priorities, such as jobs and social services. Moreover, if science and technology are associated with postmaterialist values, in a way similar to support for environmental issues (Scruggs \& Benegal 2012), we would likewise expect a general reduction in the public interest in science and less support for government spending on S\&T.

However, there is a second and opposing expectation: that science and technology policies have a strong materialist component, associated with the perception of growth, development, and the promise of increasing economic security, elements that 
become especially important in a time of crisis. As mentioned earlier, there is evidence that the scientific myth or ideology is stronger in less affluent countries or regions. Thus, citizens might express an increase in positive attitudes toward science and more support of S\&T spending as a reaction to the economic crisis, as some preliminary data suggest (Pavone et al., 2011). This is especially true to the extent science and R\&D policy have been presented in the mass media as solutions to the economic competitiveness and growth problems, and there is evidence of the impact of the media on interest in and attitudes towards science (Nisbet et al., 2002; Schäfer, 2012). In short, science and technology and related spending policies could come to be understood by citizens as materialist policies that offer a pathway out of an economic crisis $^{1}$.

These opposing expectations can be translated into the following specific hypotheses for empirical testing in the Spanish context:

1) If science is associated in the public mind with post-materialist values, then public interest in science and support for S\&T spending should decline overall and be reduced more in regions hit hardest by the economic crisis.

2) If the post-industrial model of PUS holds, and we stretch the arguments from development or levels of industrialism to the economic crisis, then public interest in

\footnotetext{
${ }^{1}$ However, the effect of any such an increase in public interest and support could prove to be short lived, if the crisis continues, S\&T does not deliver as promised, and the intensity and salience of S\&T in the mass media fades, as it has been the case in previous economic recessions (Bauer et al., 2006).
} 
science and support for S\&T spending should increase in regions hit hardest by the economic crisis.

We will test these competing hypotheses employing two national surveys from Spain, implemented before (2006) and after (2010) the onset of the economic crisis. Because the impact of the crisis has varied widely across the regions of Spain, we have the opportunity to analyze changes in public attitudes towards science and support for S\&T spending within a single country. Regions in Spain also are political entities that provide us with the opportunity to expand the PUS analysis to a more detailed level. Hopefully, the evidence from this study will help to untangle the puzzles emerging from the contradictory evidence available so far regarding the early impacts of the economic crisis on changes in general attitudes towards science and technology and public support for S\&T government spending.

\section{Data and measures}

To test our hypotheses about the potential effects of the economic crisis on attitudes toward science, we employ two complementary methods: first, we carry out a regional-level correlation analysis; and second, we conduct an individual-level difference-in-differences regression analysis. We use data from two comprehensive surveys conducted in Spain in 2006 and 2010, taking advantage of the fact that the two surveys provide snapshots of public attitudes toward science before (2006) and after (2010) the onset of the economic crisis, which emerged full force by the end of 2008. Clearly, the impact of the economic crisis on European society is complex and still ongoing (at the time of this writing). In Spain, the crisis has been especially severe but 
also quite varied across the country's 17 regions, which have diverse economies and substantially autonomous regional governments ${ }^{2}$.

The surveys were supported by Spanish Foundation for Science and Technology (Fundación Española para la Ciencia y la Tecnología -FECYT) ${ }^{3}$, the first carried out by the Spanish Center for Sociological Research (Centro de Investigaciones Sociológicas $[\mathrm{CIS}])$ and the second carried out by another survey firm. Both surveys involved inperson household interviews of randomly selected adult residents of the 17 regions of Spain, with 7056 completed interview in 2006 and 7744 completed interviews in 2010. Although the 17 regions of Spain vary greatly in population, from about 300 thousand (Rioja) to over 8 million (Andalucía), the surveys were designed to provide approximately equal-size samples for each region, thus allowing for more precise estimates of public opinion at the regional level.

As indicated, the regions of Spain vary a great deal in how deeply they were affected by the crisis. The change in unemployment from 2006 to 2010 ranged from less than 7 percentage points in some regions (Pais Vasco, Navarra, Asturias) to about 15 percentage points or more in other regions (such as Valencia, Andalucía, Murcia, and

\footnotetext{
${ }^{2}$ The Spanish Regional Governments (Comunidades Autonómas) had a significant level of policy competencies, especially in areas of health provision, social services and education; public universities also are dependent on the regional governments and R\&D is also a competence of regional governments, but shared with the national government.

${ }^{3}$ Access to the raw data, questionnaires and fieldwork design of the two surveys could be obtained at the FECYT web page: www.fecyt.es
} 
Canarias) ${ }^{4}$ (See Supplementary Table 1). We exploit this regional-level variation in the severity of the crisis to first examine the correlation of the crisis with attitudes toward science and technology at the regional level. In addition, we identify a cluster of 8 lower unemployment growth regions and a second cluster of 9 higher unemployment growth regions to compare in a difference-in-differences regression analysis. It should be pointed out that the cluster of higher unemployment regions also have higher absolute levels of unemployment in 2010, as well as having experienced greater growth in unemployment. Unemployment, we would argue, is a meaningful proxy of the overall impact of the crisis in a region and perhaps the most salient economic factor shaping public opinion.

\section{Survey measures and descriptive statistics}

The survey questions in both years asked about interest in, knowledge of, and attitudes toward S\&T, as well as basic social, economic, and political characteristics of respondents. The summary statistics for the available analytical variables are shown separately by survey wave in Table $1^{5}$.

TABLE 1 ABOUT HERE -

Beginning with the dependent variables, there are two measures of the public's general attitude toward science and technology. The first is a direct self-reported level

${ }^{4}$ Instituto Nacional de Estadística (INE). Spanish Labour Force Survey (Encuesta de Población Activa).

${ }^{5}$ For dummy variables in Table 1, the means represent proportions; the difference in means represents the change in proportions from 2006 to 2010. 
of interest in science and technology on a 1-5 scale (from 1=very uninterested to $5=$ very interested) asked a part of a list of current topics presented to respondents (including, for example, economics and business, politics, culture and the arts, sports, and so on). To make this measure consistent with our other dependent variables, which are all dummy variables, we recoded those scoring at least 3 (the midpoint) as 1 , indicating those interested in science, and recoded the rest (those scoring less than 3) as 0 . The second measure of general attitudes is a dummy variable indicating respondents who believe that, on balance, the benefits of science and technology outweigh the risks. It comes from a question in which there were two other choices (both coded zero in our analysis), specifically that the benefits and risks of S\&T were about equal, or that the risks of S\&T outweighed the benefits. As Table 1 shows, both interest in science and trust in the benefits of S\&T increased from 2006 to 2010.

There are three measures of support for government spending on S\&T in the survey. The first comes from a question that asked respondents to imagine that they could decide where to spend public funds and then showed respondents a card with the following sectors listed: public works, public safety, transportation, science and technology, environmental protection, defense, justice, culture, and sports. Respondent could choose up to three of these sectors, and we created a dummy variable that indicates respondents who chose "science and technology" as one of their three choices ${ }^{6}$. As Table 1 shows, this measure of support for S\&T spending

\footnotetext{
${ }^{6}$ The list of policies offered in this question deliberately excluded health, education, employment and pensions because these programs enjoy a wide popularity among citizens and are known to be selected as the first choices for public spending. It was a way of magnifying the visibility of science and technology policy for citizens. In a general survey (AEVAL 2011) in which all policy fields (14 different ones) were included together in the same question (in favor or against budget cuts), science and
} 
increased from 2006 to 2010. The other two measures of support for S\&T policy come from a more direct set of questions about S\&T spending by the Spanish central government and by the regional government. These questions asked whether respondents believed the government spends too much, the right amount, or too little on science and technology. We coded those who selected "too little" as an indicator of the desire for more public spending on science and technology. As Table 1 shows, support for S\&T spending as measured by these two variables declined slightly from 2006 to 2010.

The available control variables, shown in Table 1, include sex, age, education, unemployed, practicing Catholic, and political ideology. Education was operationalized as two dummy variables, one indicating a low level of education, meaning less than a full secondary education, and another indicating a high level of education, meaning the completion of at least some post-secondary education. Practicing Catholic was included as a proxy for social and religiously conservative attitudes, which may influence interest in and support of science. And political ideology, measured on 1-10 left-right scale, was included to hold constant differences in political values and preference across regions and over time. Except for gender, the mean values for these control variables reveal changes from 2006 to 2010. As expected, the proportion of unemployed people in the sample nearly doubled from 2006 to 2010. In addition, the respondents seem to have become somewhat more conservative politically, perhaps because the left-leaning PSOE party was in power as the crisis unfolded in Spain (and technology policy resulted the third policy field having less opposition to budget cuts, just before "defense" and "public works", but after "culture", "transportation", "justice", "environment" and to a big distance of the set of policies related to the welfare state. 
indeed would come to be defeated by the right-leaning PP in the 2011 national elections). Changes over time in some of the other variables are less easily explained (fewer practicing Catholics in 2010, for example) but could be due to differences in sampling and survey procedures, as the 2010 survey was conducted by a different firm than the 2006 survey. Thus, it is important to control for these variables in the analysis.

\section{Analysis and Results}

Our analysis will proceed in two steps. First, we begin with simple regional-level correlations between changes in unemployment and changes in attitudes toward science and support for S\&T spending by government. Next, we conduct an individuallevel analysis using a differences-in-differences regression strategy, which will be explained shortly. Employing both approaches provides a more robust test of our hypotheses.

\section{Regional-level correlations}

To produce the regional-level correlations, we aggregated individual survey data to the regional level by calculating the regional means for each of the 5 survey measures selected as dependent variables (see again Table 1) in 2006 and 2010, then calculated the change in each measure for each region. Next, we correlated this change in attitudes toward science and S\&T spending with the change in regional unemployment (see Supplementary Table 1). We ran significance tests on the correlations, but with only 17 regions the statistical power is inevitably limited. The main results are shown in the first column of Table 2 . 


\section{- $\quad$ TABLE 2 ABOUT HERE -}

As can be seen, all of the correlations are positive and at least moderately strong (Cohen, 1992), indicating that the steeper the rise in unemployment from 2006-2010 in a region, the greater the increase in positive attitudes, although only the correlation with science as a priority for government spending is statistically significant. Figure 1 illustrates this one correlation visually and also suggests that the region of Murcia is somewhat of an outlier with a fair amount of leverage in the correlations (given that it has a rather high value for $X$, or change in unemployment). Murcia is a small region on the southeast coast of the country that was hard-hit by the crash of the property market and the decline in tourism in Spain. ${ }^{7}$

\section{-FIGURE 1 ABOUT HERE-}

Table 2 also shows the correlations with the outlier Murcia removed (thus leaving only 16 regions included in the correlations). Three of the correlations become much stronger and statistically significant: interest in science, trust in the benefits of S\&T, and especially selecting S\&T as priority for government spending. Two of the correlations become weaker with the outlier removed: believing the central government spends too little on S\&T and believing the same thing about the regional

\footnotetext{
${ }^{7}$ The explanations of the outlier position of Murcia could be of two types: a) One related to the implementation of field work; we have found no clear arguments in this area. b) The substantive one could be connected with the early relevance in the Region of the fact that regional Government was the one having the biggest deficit in Spain. Then the effect of that perception about excessive public spending and excessive deficit could have produce a radical (and early) change in the regional public. The point for further research is to what extent the notice by the public (and the media impact) of the budget deficit situation will have impacted in other regions latter on.
} 
government. As will be seen shortly, the pattern of results seen in the second column of Table 2 (without the outlier Murcia) closely parallels the results from the individuallevel regressions.

In sum, all of the regional correlations in Table 2-with and without the outlier Murcia-are positive and at least moderately large in magnitude. Although the statistical significance tests are inconsistent, because of the small sample size, still the overall pattern of results is consistent with the hypothesis that regions of Spain in which unemployment increased the most experienced generally changes to a more positive attitudes toward science and greater proportion selecting S\&T as a priority for public spending.

\section{Individual-level difference-in-differences analysis (DiD)}

It is useful to test the hypothesis at the individual-level of analysis as well. To do this, we employ a difference in differences statistical strategy, pooling the two crosssectional surveys, to compare change in science attitudes in the high-unemployment regions to change over the same period in the low-unemployment regions. In a regression framework, our model is as follows (based on Remler \& Van Ryzin, 2011):

$$
\hat{Y}=a+b_{\mathrm{R}} \mathrm{R}+b_{T} T+b_{\mathrm{int}}(\mathrm{R} \times T)+b_{\mathrm{c} 1} \mathrm{C} 1+\ldots b_{\mathrm{cj}} \mathrm{Cj}
$$

Where $\hat{Y}$ is a measure of attitudes towards science; $\mathrm{R}$ is a dummy variable indicating a respondent from a region with high unemployment; $\mathrm{T}$ is a dummy variable coded 0 for the pre-crisis period (2006) and 1 for the post-crisis period (2010); $\mathrm{R} \times \mathrm{T}$ is an interaction 
term; and C1 through $\mathrm{Cj}$ are control variables added to the model. The slope $b_{R}$ estimates the difference in science attitudes $(Y)$ between the high and low unemployment regions during the pre-crisis period and is assumed constant over time. The slope $b_{T}$ estimates the difference in science attitudes $(\mathrm{Y})$ between the pre- and post-reform period for the low unemployment regions and is thus assumed to be the trend that would have occurred in high unemployment regions, had the crisis not affected attitudes differentially. Finally, the slope on the interaction $b_{\text {int }}$ estimates the difference in differences or the net difference (from the trend) in the dependent variable $(\mathrm{Y})$ for the high unemployment regions and is thus the presumed causal effect of the crisis on attitudes toward science and technology.

Because our dependent variables are all dichotomous, we ran the difference in differences analysis using probit and report the results as marginal effects ${ }^{8}$. Table 3 shows the results for the general attitudes toward science, including interest in science and trust that the benefits of S\&T outweigh the risks. We also include results for interest in the environment and ecology for comparison purposes, as it is a policy area that previous studies have shown to be clearly postmaterialist. For each outcome, two models are shown: a basic difference in differences model, without control variables, and another model with adjustment for the seven available control variables. This was done to provide some sense of the sensitivity of the results to potential confounding

\footnotetext{
${ }^{8}$ Marginal effects, which for the time, region, and time $\mathrm{x}$ region interaction (all dummy variables) are interpretable as the percentage-point change in the probability that $Y=1$ for a discrete (0-1) change in $\mathrm{X}$ (with the other variables at the mean). We estimated all of the models also using OLS, or linear probability methods (not presented here), and we obtained substantially the same results. We used Stata 12 and the dprobit command for the models shown.
} 
from these control variables. The main coefficient of interest is the interaction term, which represents the net change in the probability of the outcome in higherunemployment regions relative to the change over time that occurred in the lowerunemployment regions.

\section{-TABLE 3 ABOUT HERE-}

As Table 3 shows, interest in science significantly increased in higher-unemployment regions, relative to the change that occurred in lower-unemployment regions. The coefficient (focusing on the full model with control variables), indicates a net gain of nearly 6 percentage points in the level of interest in science in higher-unemployment regions of Spain compare with low-unemployment ones. The net gain in trust that the benefits of S\&T outweigh the risks is even larger, nearly 14 percentage points. At the same time there is no change in interest in the level of interest in environmental issues.

Although not of primary interest, it is worth noting that most of the control variables included in the models in Table 3 are also significant and consistent with previous research. The biggest effect comes from having a low educational level, which reduces interest in S\&T by nearly 18 points and trust by 13 points. Having a postsecondary education, in contrast, increases interest in science by 16 points and trust by 15 points. Females have less interest and trust in science than males. Older people express less interest in science, but at the same time have more trust. Political ideology (being more conservative) follows a similar pattern in that it is negatively associated with interest and positively associated with trust, although this last relationship is not 
significant statistically. Unemployed people generally have lower levels of both interest in and trust of S\&T.

Table 4 presents the probit analysis of support for government spending on S\&T. Again focusing on the interaction term, the higher-unemployment regions experienced an increase of nearly 6 percentage points, relative to the change in the lowerunemployment regions, in the proportion of people selecting science and technology as a priority for government investment. But the probit analysis in Table 5 does not indicate much of a difference between higher- and lower-unemployment regressions with respect to the view that central government is spending too little on S\&T. Similarly, there is no difference-in-differences regarding the view that the regional government spends too little on S\&T.

\section{-TABLE 4 ABOUT HERE-}

Regarding the control variables in Table 4, again having a secondary education has the largest effect, increasing support by 15 points. Being a female, older, a practicing Catholic, and having a conservative ideology are all negatively associated with the choice of S\&T as a priority for government spending. Being unemployed is also negatively related to support for government spending on S\&T.

\section{Discussion and implications}

Both the aggregate correlations at regional level and the individual-regressions in our study show that, in regions hit hardest by the economic crisis (compared to lessaffected regions), trust in the benefits of S\&T increased substantially, as did general 
interest in science. In addition, residents of the hardest-hit regions were more likely to choose S\&T (out of a list of policy areas) after the crisis as a priority for government. With respect to our original expectations and hypotheses, these findings are consistent with the post-industrial model of PUS and its argument about the salience of the scientific myth in less economically prosperous societies. In addition, the findings also correspond to the idea that science and technology have been understood by Spanish citizens as materialist policies that provide important opportunities to recover from an economic crisis, even if we must note a caveat that only the early effects of the economic crisis are evident in our 2010 data and that the Spanish public's views may change as the crisis continues to unfold.

We think it is especially significant that in regions with higher increases in unemployment, residents have also increased their level of expressed priority for government spending in S\&T. These results again suggest that S\&T policy is perhaps seen as a way out of the economic crisis and a change of the productive model, with a more relevant role for knowledge. Thus, these results provide confirmation that the public perceives S\&T spending as a largely materialist policy, unlike how they view environmental policy which is more clearly associated with post-materialist values. When we analyze the assessment of the citizens with respect to the actual level of spending in S\&T by the Spanish central and regional governments, however, we found little association with the economic crisis. Globally, these findings regarding S\&T government spending support are consistent with the general descriptive results from AEVAL (2011), when including all policy fields (welfare policies included). 
Caveat about the interpretation of our results should be noted, however. To begin with, as noted earlier, our results could just be a reflection of the early stages of the crisis, in 2010 (indeed, at the time of this writing, 2012, the economic crisis in Spain is still ongoing). The process of deepening crisis could produce still further changes in the public's assessment of the contribution of science and technology to the economic recovery. Further waves are planned for the survey, so it will be possible in future analyses to the trends to see if the increases in interest and trust in science, as well as the gains in support for to S\&T as a priority for government spending, hold up over the longer term.

This association between S\&T and hopes for economic recovery, it must be emphasized, could well have been shaped by the mass media. It is well know that attitudes towards issues and spending are significantly affected by mass media salience (Schneider \& Jacoby, 2005). Spanish mass media have been very active during the study period constructing a discourse of science and technology connected with improvements of future economic condition in Spain. Moreover, government policy between 2006 and 2009 provided an official discourse that also made the same connection between economic growth and science and technology. As the crisis has deepened in Spain and the media and official discourse have begun to shift toward more pressing issues of economic survival (unemployment benefits, education provision, health cost and cuts, etc.), then it remains to be seen whether science and technology continue to be mythologized or associated in the long run with the materialist domain in the public mind. 
The findings for our control variables, although not the primary focus, are worth discussing briefly in relation to previous research. High levels of education predict higher levels of interest and in more positive attitudes towards science, confirming previous findings that education level is a strong predictor of support for science (Miller et al., 1997). Being a female produces a negative effect on interest in and perceived benefits of science. This is also consistent with previous research that has found women to express less interest in and more skepticism about science, while at the same time the general literature of public spending finds women to be more supportive of social welfare policies. Ideology and religious belief, when significant, also produce effects consistent with what previous research has found, namely that left-oriented and non-Catholics are somewhat more supportive of science developments (Miller et al., 1997; Nisbet, 2005). Globally, positive attitudes towards science have been linked with younger, male, and more educated people (Miller, 1983b) and looks like the effect of the crisis is reinforcing the impact of these variables on the interest and positive attitudes. While less educated people, unemployed and women tend to contribute to the reduction of the interest and positive assessment as a consequence of the crisis. Our study contributes some preliminary empirical evidence of the impact of an economic crisis on attitudes towards science and support for government spending on S\&T. However, there are many additional issues and avenues for future research. Our finding of an increase in the priority given by the public to government S\&T spending contrasts with the Spanish government's austerity policies, which have resulted in large cuts to the public budgets for scientific research and technological development. Are there potential political consequences in this contradiction between popular priorities and official policies? Much depends, of 
course, on how long-lived this increase in interest, trust, and support for S\&T spending turns out to be. Is it a short-term trend (as the potential outlier region we found suggests) or will it persist throughout the duration of the crisis? We have suggested some intuitions and speculations on the impact of the mass media on the attitudes and preferences, but it would be important to investigate this possible mechanism more explicitly. Is support for science in the aftermath of a crisis a media effect? And if so, will its influence fade as the public deficit debates and social hardships take over the front pages, reducing the salience of science and technology in the media? There are also important questions that should be further explored regarding the impact of people's personal situation on their science attitudes. Our results suggest that, although economically hard-hit regions generally experienced more positive attitudes toward science, unemployed people individually have less positive attitudes towards science and government S\&T spending. To what extent is the change in attitudes toward science being driven by those directly affect by the crisis, or (as our pattern of results suggests) by those in society who are less directly affected?

Finally, we should point out that our study has both methodological strengths and weaknesses. It is somewhat unique in analyzing these issues from a regional point of view. Regions as a unit of analysis are important elements to improve our knowledge, especially if we think in terms of science in society. But Spain is a country especially hard hit by the crisis, and it is important to look at these issues also cross-nationally, perhaps using data from the Eurobarometer or European Social Survey. In our study, we were also limited in that we were able to compare and pool data from only two snapshots in time. Although this has important advantages over a simple cross- 
sectional survey, there is a need for serious longitudinal analysis, with permanent

panels of individual, to really analyze changes in attitudes in the same cohorts and not

just changes that could be attributed to other factors, such as the composition of the

sample. Still, we would argue that our study at least opens the door to future

investigations of the relationship between economic cycles and the public's

understanding of science.

\section{Acknowledgments}

An early draft of this paper was presented at a panel organized by the RC35 (Technology and Development) of the International Political Science Association (IPSA) while the XXII World Congress of Political Science held in Madrid, 8-12 July 2012. We thanks participants for the comments and discussion as much as the PUS anonymous reviewers and the editor for the suggestions and criticisms.

We also thank the Fundación Española para la Ciencia y Tecnologia (FECYT) for providing us access to the data of the Encuesta de Percepción Publica de la Ciencia.

This research has been funded by the Spanish National R\&D Plan (Ministry of Science and Innovation grant CSO-2008-03100 and Ministry of Economic Affairs and Competitiveness CSO-2011CSO2011-29431) and the 2011 CSIC-IPP Short Term Visiting Fellows Program (IPP-2011-VF-03) that partially funded a short term visit of Gregg G. Van Ryzin to Madrid.

\section{References}

Agencia de Evaluación y Calidad [AEVAL] (2011). La Administración Pública a juicio de los ciudadanos: satisfacción con los servicios, valoración del gasto, confianza en los empleados públicos y actitudes hacia la e-administración. Madrid: AEVAL.

Allum, N., Patrick Sturgis, P., Tabourazi, D. \& Brunton-Smith, I. (2008). Science knowledge and attitudes across cultures: a meta-analysis. Public Understanding of Science, 200817 (1), 35-54.

Bauer, M.W. (2002). Controversial medical and agri-food biotechnology: A cultivation analysis. Public Understanding of Science, 11(2), 93-111.

Bauer, M.W. (2009). The Evolution of Public Understanding of Science--Discourse and Comparative Evidence. Science, Technology \& Society, 14(2), 221-240.

Bauer, M.W., Allum, N. \& Miller, S. (2007). What can we learn from 25 years of PUS survey research? Liberating and expanding the agenda. Public Understanding of Science, 16 (1), 79-95.

Bauer, M., Durant, J. \& Evans, G. (1994). European Public Perceptions of Science. International Journal of Public Opinion Research, 6(2), 163-186.

Bauer, M.W., K. Petkova, P. Boyadjieva \& G. Gornev (2006). Long-term Trends in the Representations of Science Across the Iron Curtain: Britain and Bulgaria, 1946-95, Social Studies of Science, 36(1), 97-129.

Blekesaune, M. \& Quadagno, J. (2003). Public Attitudes toward Welfare State Policies: A Comparative Analysis of 24 Nations, European Sociological Review, 19 (5), 415-427.

Cohen, J. (1992). A power primer. Psychological Bulletin, 112(1), 155-159. 
Durant, J., Bauer, M., Gaskell, G., Midden, C., Liakopoulos, M. \& Scholten, L. (2000). Two Cultures of Public Understanding of Science and Technology in Europe. In Dierkes, M. \& von Grote, C. (eds.) Between Understanding and Trust. The Public, Science and Technology, (pp.131-156). London: Routledge (reprint 2003).

Eurobarometer (2010a). Europeans and the crisis. Eurobarometer 74.1. Brussels: TNS Oppinion and Social.

Eurobarometer (2010b). Science and technology. Special Surobarometer 340. Wave 73.1. Brussels: European Commission.

Fraile, M. \& Ferrer, M. (2005). Explaining the Determinants of Public Support for Cuts in Unemployment Benefits Spending across OECD Countries. International Sociology, 20 (4), 459481.

Gaskell, G., Bauer, M.W., Durant, M. \& Allum, N.C. (1999). World apart? The reception of genetically modified foods in Europe and in U.S. Science, 285, 384-387.

Inglehart, R. (1990), Culture shift in advanced industrial society. Princeton N. J.: Princeton University Press.

Inglehart, R. \& Abramson, P.R. (1994). Economic Security and Value Change. The American Political Science Review, 88 (2), 336-354.

Jacoby, W. G. (1994). Public Attitudes toward Government Spending. American Journal of Political Science, 38 (2), 336-361.

Kam, C.D. \& Nam, Y. (2008). Reaching out or Pulling Back: Macroeconomic conditions and Public Support for Social Welfare Spending. Political Behavior, 30 (2), 223-258.

Miller, J.D. (1983a). Scientific Literacy: A Conceptual and Empirical Review. Daedalus, 112(2), 2948.

Miller, J.D. (1983b). The American people and science policy. The role of public attitudes in the policy process. New York: Pergamon Press.

Miller, J.D. (1998). The measurement of civic scientific literacy. Public Understanding of Science, 7(3), 203-223.

Miller, J.D. (2004). Public Understanding of, and Attitudes toward, Scientific Research: What We Know and What We Need to Know. Public Understanding of Science, 13(3), 273-294.

Miller, J.D., Pardo, R. \& Niwa, F. (1997). Public perceptions of science and technology. A comparative study of the European Union, the United States, Japan and Canada. Madrid: Fundación BBV.

Monroe, A.D. (1979). Consistency between Public Preferences and National Policy Decisions. American Politics Research, 7 (1), 3-19.

Muñoz, A., Moreno, C. \& Luján, J.L. (2012) Who is willing to pay for science? On the relationship public perceptions of science and the attitudes to public funding of science. Public Understanding of Science 21 (2), 242-253.

Nisbet M.C. (2005). The Competition for Worldviews: Values, Information, and Public Support for Stem Cell Research". International Journal of Public Opinion Research, 17 (1), 90-112.

Nisbet, M.C., Scheufele, D.A., Shanahan, J., Moy, P., Brossard, D. \& Lewenstein, B.V. (2002). Knowledge, Reservations, or Promise?: A Media Effects Model for Public Perceptions of Science and Technology. Communication Research, 29 (5), 584-608.

OECD (2009). Policy Responses to the Economic Crisis: Investing in Innovation for Long-Term Growth. Paris: OECD, June 2009. 
Pardo, R. \& Calvo, F. (2002). Attitudes toward science among the European public: a methodological analysis. Public Understanding of Science, 11(2), 155-195.

Pavone, V., Osuna, C. \& Degli Espositi, S. (2011). Invertir en ciencia y tecnologia en tiempos de austeridad economica: ¿Qué opinan los ciudadanos". In FECYT (2011) Percepción Social de la Ciencia y la Tecnología 2010, (pp. 115-136). Madrid: FECYT.

Quadagno, J. \& Pederson, J. (2012). Has support for Social Security declined? Attitudes toward the public pension scheme in the USA, 2000 and 2010. International Journal of Social Welfare, 21, s88-.s100.

Quintanilla, M.A. \& Escobar, M. (2005). Un indicador de cultura científica para las comunidades autónomas. FECYT (2005). Percepción Social de la Ciencia y la Tecnología en España - 2004, (pp. 223-232). Madrid: FECYT.

Quintanilla, M.A., Escobar, M. \& Quiroz, K. (2011). La actitud global hacia la ciencia en las comunidades autónomas. FECYT (2011) Percepción Social de la Ciencia y la Tecnología 2010, (pp. 137-158) Madrid: FECYT.

Remler, D.K. \& Van Ryzin, G.G. (2011). Research Methods in Practice. Los Angeles: SAGE Publications.

Sanders, A. (1988). Rationality, self-inters, and Public Attitudes on Public Spending. Social Sciences Quarterly, 69 (2), 311-324.

Sanz-Menéndez, L., Van Ryzin, G.G. \& del Pino, E. (2013). Citizens' support for government spending on science and technology. CSIC-IPP Working Paper 2013-1, available at: http://digital.csic.es/browse?type=author\&value=Sanz+Men\%C3\%A9ndez\%2C+Luis $\quad$ (last access May $10^{\text {th }}$ 2013). (Submitted to Science and Public Policy)..

Science (2012). Research cuts will cause 'Exodus' from Spain. Science 336, 13 april 2012, 139-140

Scruggs, L. \& Benegal, S. (2012). Declining public concern about climate change: Can we blame the great recession? Global Environmental Change, 22 (2), 505-515.

Schäfer, M.S. (2012). Taking stock: A meta-analysis of studies on the media's coverage of science. Public Understanding of Science, 21(6), 650-663

Schneider, S.K. \& Jacoby, W.G. (2005). Elite Discourse and American Public Opinion: The Case of Welfare Spending. Political Research Quarterly, 58 (3), 367-379.

Sturgis, P. \& Allum, N. (2004). Science in Society: Re-Evaluating the Deficit Model of Public Attitudes. Public Understanding of Science, 13(1), 55-74.

Svallfors, S. (1997). Worlds of Welfare and Attitudes to Redistribution: A Comparison of Eight Western Nations. European Sociological Review, 13, 283-304.

Svallfors, S. (2003). Welfare Regimes and Welfare Opinions: A Comparison of Eight Western Countries. Sociol Indicators Research, 64, 495-520.

Taylor-Gooby, P. (2001). Sustaining State Welfare in Hard Times: Who Will Pay for the Bill?. Journal of European Social Policy, 11, 133-47.

US NSF (2012). Science and Engineering Report 2012, Chapter 7: Science and Technology: Public Attitudes and Understanding. Washington DC: US NSF. 
TABLE 1. Descriptive statistics and 2006-2010 differences

\begin{tabular}{|c|c|c|c|c|c|c|}
\hline & & & 2006 & 2010 & & \\
\hline & Min & Max & Mean & Mean & Diff. & \\
\hline \multicolumn{7}{|l|}{ Dependent variables } \\
\hline \multicolumn{7}{|l|}{ General attitudes toward science } \\
\hline Interest in S\&T (1=interested, $0=$ not interested) & 0 & 1 & 0.62 & 0.71 & 0.09 & $* * *$ \\
\hline Trust that benefits of S\&T outweigh risks ( $1=y e s, 0=$ no) & 0 & 1 & 0.46 & 0.52 & 0.07 & $* * *$ \\
\hline \multicolumn{7}{|l|}{$\underline{\text { Suppor for S\&T policy }}$} \\
\hline S\&T seen as a priority for public spending ( $1=y e s, 0=$ no) & 0 & 1 & 0.20 & 0.26 & 0.06 & $* * *$ \\
\hline Central gov't spends too little $S \& T(1=y e s, 0=n o)$ & 0 & 1 & 0.49 & 0.45 & -0.04 & $* * *$ \\
\hline Regional gov't spend too little S\&T (1=yes, $0=$ no) & 0 & 1 & 0.49 & 0.48 & -0.01 & \\
\hline \multicolumn{7}{|l|}{ Control variables } \\
\hline Female ( $1=y e s /$ female, $0=$ no/male) & 0 & 1 & 0.51 & 0.52 & 0.01 & \\
\hline Age (in years) & 0 & 98 & 45.16 & 44.33 & -0.83 & $* * *$ \\
\hline Low education (less than secondary) & 0 & 1 & 0.28 & 0.21 & -0.07 & $* * *$ \\
\hline High education (some post-secondary) & 0 & 1 & 0.14 & 0.18 & 0.05 & $* * *$ \\
\hline Unemployed ( $1=$ yes, $0=$ no) & 0 & 1 & 0.06 & 0.11 & 0.05 & $* * *$ \\
\hline Practicing Catholic ( $1=y e s, 0=$ no) & 0 & 1 & 0.28 & 0.19 & -0.09 & $* * *$ \\
\hline Ideology ( $1=$ far left to $10=$ far right) & 1 & 10 & 4.61 & 5.03 & 0.43 & $* * *$ \\
\hline
\end{tabular}

Note: Sample size $\mathrm{n}=7056$ in 2006 and $\mathrm{n}=7744$ in $2010 ;{ }^{* * *} \mathrm{p}<.01,{ }^{* *} \mathrm{p}<.05, * \mathrm{p}<.10$ (two-tailed $\mathrm{z}$-test for proportions, t-test for means). 
Table 2. Regional-level correlations of change in unemployment with change in atttidues

\begin{tabular}{|c|c|c|}
\hline \multirow[b]{2}{*}{ 2006-10 change in ... } & \multicolumn{2}{|c|}{ 2006-10 change in unemployment } \\
\hline & $\begin{array}{r}\text { All regions } \\
(n=17)\end{array}$ & $\begin{array}{r}\text { Murcia } \\
\text { excluded } \\
(n=16)\end{array}$ \\
\hline Interest in S\&T & 0.25 & $0.42 *$ \\
\hline Trust that benefits of S\&T outweigh risks & 0.30 & $0.51 * *$ \\
\hline S\&T seen as a priority for public spending & $0.42 *$ & $0.66 * * *$ \\
\hline Central gov't spends too little S\&T & 0.30 & 0.24 \\
\hline Regional gov't spend too little S\&T & 0.39 & 0.32 \\
\hline
\end{tabular}

Note: ${ }^{* *} \mathrm{p}<.01, * * \mathrm{p}<.05, * \mathrm{p}<.10$ (two-tailed test) 
Table 3. Difference in differences analysis of general attitudes toward science, technology, and the environment (probit regressions showing marginal effects)

\begin{tabular}{|c|c|c|c|c|c|c|c|c|c|c|c|c|}
\hline & \multicolumn{4}{|c|}{$\begin{array}{l}\text { Interest in science and } \\
\text { technology (S\&T) }\end{array}$} & \multicolumn{4}{|c|}{$\begin{array}{c}\text { Trust that benefits of S\&T } \\
\text { outweigh risks }\end{array}$} & \multicolumn{4}{|c|}{$\begin{array}{l}\text { Interest in the environment } \\
\text { and ecology }\end{array}$} \\
\hline Time & 0.057 & $* * *$ & 0.047 & $* * *$ & -0.020 & $*$ & -0.027 & $* *$ & -0.013 & & -0.011 & \\
\hline Region & 0.011 & & 0.007 & & -0.089 & $* * *$ & -0.080 & $* * *$ & 0.028 & $* * *$ & 0.027 & $* * *$ \\
\hline Time $\mathrm{x}$ Region & 0.064 & $* * *$ & 0.056 & $* * *$ & 0.157 & $* * *$ & 0.138 & $* * *$ & 0.017 & & 0.005 & \\
\hline Female & --- & & -0.084 & $* * *$ & --- & & -0.041 & $* * *$ & --- & & 0.029 & $* * *$ \\
\hline Age & --- & & -0.003 & $* * *$ & --- & & 0.001 & $* * *$ & --- & & 0.000 & $*$ \\
\hline Low education & --- & & -0.177 & $* * *$ & --- & & -0.129 & $* * *$ & --- & & -0.132 & $* * *$ \\
\hline High education & --- & & 0.160 & $* * *$ & --- & & 0.151 & $* * *$ & --- & & 0.048 & $* * *$ \\
\hline Unemployed & --- & & -0.028 & $*$ & --- & & -0.033 & $* *$ & --- & & 0.001 & \\
\hline Practicing Catholic & --- & & 0.015 & & --- & & -0.038 & $* * *$ & --- & & -0.001 & \\
\hline Ideology & --- & & -0.007 & $* * *$ & --- & & 0.003 & & --- & & -0.017 & $* * *$ \\
\hline Pseudo R-square & 0.010 & & 0.088 & & 0.008 & & 0.029 & & 0.002 & & 0.031 & \\
\hline Observed P & 0.668 & & 0.667 & & 0.493 & & 0.495 & & 0.801 & & 0.800 & \\
\hline Predicted P (at X-bar) & 0.670 & & 0.681 & & 0.493 & & 0.495 & & 0.802 & & 0.807 & \\
\hline Obs (n) & 14612 & & 14039 & & 14700 & & 14113 & & 14596 & & 14017 & \\
\hline
\end{tabular}

Note: Coefficients shown are marginal effects and interpretable as changes in probability; $* * * \mathrm{p}<.01 * * \mathrm{P}<.05 * \mathrm{p}<.10$ (two-tailed tests). 
Table 4. Difference in differences analysis of support for government science and technology spending (probit regressions showing marginal effects)

\begin{tabular}{|c|c|c|c|c|c|c|c|c|c|c|c|c|}
\hline \multirow[b]{2}{*}{ Time } & \multicolumn{4}{|c|}{$\begin{array}{l}\text { S\&T chosen as a priority for } \\
\text { public spending }\end{array}$} & \multicolumn{4}{|c|}{$\begin{array}{c}\text { Central gov't spends too little } \\
\text { on S\&T }\end{array}$} & \multicolumn{4}{|c|}{$\begin{array}{c}\text { Regional gov't spends too } \\
\text { little on S\&T }\end{array}$} \\
\hline & 0.019 & $*$ & 0.016 & & -0.059 & $* * *$ & -0.066 & $* * *$ & $-0.027 *$ & $* *$ & -0.033 & $* *$ \\
\hline Region & -0.009 & & -0.008 & & -0.001 & & 0.000 & & -0.016 & & -0.018 & \\
\hline Time $x$ Region & 0.072 & $* * *$ & 0.055 & $* * *$ & 0.043 & $* * *$ & 0.026 & & 0.028 & & 0.011 & \\
\hline Female & --- & & -0.049 & $* * *$ & --- & & -0.068 & $* * *$ & --- & & -0.055 & $* * *$ \\
\hline Age & --- & & -0.001 & $* * *$ & --- & & 0.001 & $* * *$ & --- & & 0.001 & $* *$ \\
\hline Low education & --- & & -0.096 & $* * *$ & --- & & -0.126 & $* * *$ & --- & & -0.116 & $* * *$ \\
\hline High education & --- & & 0.153 & $* * *$ & --- & & 0.128 & $* * *$ & --- & & 0.128 & $* * *$ \\
\hline Unemployed & --- & & -0.021 & $*$ & --- & & 0.021 & & --- & & 0.031 & $* *$ \\
\hline Practicing Catholic & --- & & -0.017 & $*$ & --- & & -0.034 & $* * *$ & --- & & -0.047 & $* * *$ \\
\hline Ideology & --- & & -0.009 & $* * *$ & --- & & -0.007 & $* * *$ & --- & & -0.009 & $* * *$ \\
\hline Pseudo R-square & 0.007 & & 0.053 & & 0.002 & & 0.024 & & 0.000 & & 0.023 & \\
\hline Observed P & 0.227 & & 0.226 & & 0.469 & & 0.469 & & 0.487 & & 0.487 & \\
\hline Predicted P (at X-bar) & 0.226 & & 0.213 & & 0.469 & & 0.468 & & 0.487 & & 0.487 & \\
\hline Obs (n) & 14800 & & 14204 & & 14746 & & 14161 & & 14739 & & 14155 & \\
\hline
\end{tabular}

Note: Coefficients shown are marginal effects and interpretable as changes in probability; ${ }^{* * *} \mathrm{p}<.01{ }^{* *} \mathrm{P}<.05 * \mathrm{p}<.10$ (two-tailed tests). 
Figure 1. Scatterplot showing regional-level correlation between change in unemployment and change in views of S\&T as a priority for government spending

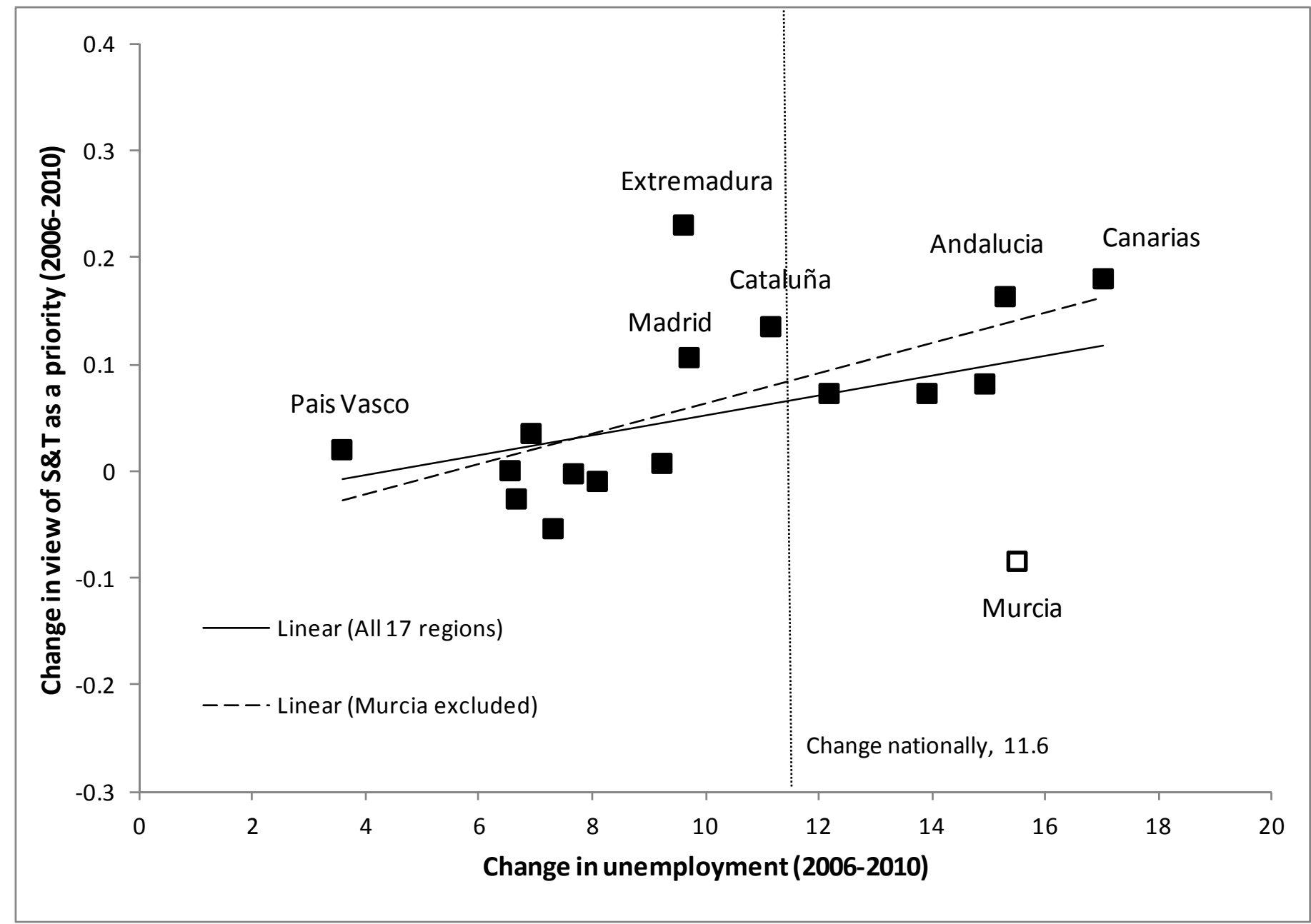


Supplementary Table 1. Unemployment rates by Region 2006 and 2010 (in percentages, \%)

\begin{tabular}{|l|r|r|r|}
\hline & 2006 & 2010 & Change \\
\hline Lower unemployment & & & \\
\hline País Vasco & 7.0 & 10.6 & 3.6 \\
\hline Navarra & 5.3 & 11.9 & 6.6 \\
\hline Asturias & 9.3 & 16.0 & 6.7 \\
\hline Galicia & 8.5 & 15.4 & 6.9 \\
\hline Cantabria & 6.6 & 13.9 & 7.3 \\
\hline Castilla y León & 8.1 & 15.8 & 7.7 \\
\hline Rioja & 6.2 & 14.3 & 8.1 \\
\hline Aragón & 5.5 & 14.8 & 9.2 \\
\hline Higher unemployment & & & \\
\hline Extremadura & 13.4 & 23.0 & 9.6 \\
\hline Madrid & 6.4 & 16.1 & 9.7 \\
\hline Cataluña & 6.6 & 17.8 & 11.2 \\
\hline Castilla--La Mancha & 8.8 & 21.0 & 12.2 \\
\hline Balears & 6.5 & 20.4 & 13.9 \\
\hline Valenciana & 8.4 & 23.3 & 14.9 \\
\hline Andalucía & 12.7 & 28.0 & 15.3 \\
\hline Murcia & 7.9 & 23.4 & 15.5 \\
\hline Canarias & 11.7 & 28.7 & 17.0 \\
\hline National total & 2.5 & 20.1 & 11.6 \\
\hline
\end{tabular}

